\title{
Research of the Thermal Gradient and Quality of Welded Joints from PVC Thermoplastics Foils at High Frequency Symmetric Welding
}

\begin{abstract}
ION MITELEA, ILARE BORDEASU*, NICOLAIE VARZARU, ION DRAGOS UTU*
University Politehnica Timisoara, 2 Piata Victoriei Sq., 300006, Timisoara, Romania

Extending of the welding application field by high frequency currents of the thermoplastic polymers requires the full knowledge of the physical parameters which characterize the joining process of the welded joint. Since these engineering materials are extremely sensitive to temperature variations, the present paper highlights the role of the thermal gradient in obtaining of some welded joints with high mechanical strength and free from continuity defects. Regarding this, it is demonstrated that increasing the thickness of the polyvinyl chloride films, from 0.4 to $1 \mathrm{~mm}$, the heat effect in the contact area of the electrodes is keptand the welding process has a high stability. For a well-run welding process is obtained a uniform distribution of the molten material in the joint area with positive impact on the breaking force values.
\end{abstract}

Keywords: high frequency welding, PVC foils, thermal gradient, quality

Welding assembly of polymeric materials, currently, knows a continuous development from both material involved and in terms of potential applications $[1-3,9,10]$.

In this context, high frequency (HF) welding is a joining process that offers many advantages such as: dimensional accuracy, flexibility, control and automation facility, etc. $[4,5]$. During decades, the researches performed in this area aimed both aspects related to welding sources and modeling phenomena occurred at the interaction of the electromagnetic field - polymer.

Despite these constant concerns the current level in the control and optimization of process parameters remains one based on experimental tests. The difficulties encountered are related to the knowledge of the materials properties to be joined, in particular, how they respond to the high frequency current action [6,7]. Therefore, this paper aims to study the importance of the thermal gradient on the cross section of HF performed welds of some polymers on their quality.

\section{Experimental part}

Byintroducing a dielectric material in an electric field, a part of the field energy is dissipated in the substance, being transformed into heat in most cases. Material energy dissipated per time unit under the influence and on behalf of the electric field constitutes the dielectric losses (of the material to be welded). Since the polymers are poorly electrically conductive materials with a high dielectric constant, they act as a dielectric between the electrodes of the welding die; they are heated and under the pressure of the electrodes and after cooling time the welded joint is achieved.

Thermoplastic materials that exhibit good weldability by $\mathrm{HF}$ are $[3,6,9,10]$ :

- polyvinyl chloride (PVC) soft and hard;

- polyamides (PA);

- polyester (PES);

- thermoplastic polyurethane (TPU);

- some types of composite materials (TPO).

A HF mold welding can use up to two material layers with thickness between 0.2 to $5 \mathrm{~mm}$.

The materials can be welded without equipment constraints if there are sized to a maximum of $20 \mathrm{~cm}^{2} / \mathrm{kW}$.
The welding machine used in experiments [7] contains an induction coil which is supplied with radio-frequency electrical currents. It generates a high frequency electromagnetic field that acts as a electric capacitor (welding tool as reinforcements and the material to be welded as dielectric).

The symmetrical high frequency (HF) welding has the particularity to use a lower electrode. Generally the lower electrode represents the mirror view of the electrode or with a slight deviation from it. The symmetrical welding was the first application of HF welding process, because the symmetry ensure stabile and constant electrical field and melt material flow.

Applications of this process are met in all the industries:

- packaging with plastic products as bags, boxes etc,

- medical with plastic bags, perfusions etc,

- automotive with plastic components (sunblind, carpets etc),

- other applications: plastic covers, light plastic structures etc.

After HF welding some products must be cut to reach the final product.

To reduce production costs has raised the idea of developing a combined technological application to perform welding and cutting plastic sheets in one single step.

So instead of simply welding electrodes shown in figure 2 , there are used sharp electrodes equipped with cutting edge shown in figure 1.

The HF symmetrical welding process can be:

- simple presented in figure 1, where the foils are just welded.

- combined presented in figure2, where the foils are welded and cut simultaneous.

The difference of the process variants, presented above, is the geometry of the electrode.

For combined HF welding symmetrical process to obtain an easy cutting process it is applied the cutting edge only to the upper electrode, while the lower electrode has a slot (fig. 2).

One of the advantages of symmetrical HF welding is also the visual appearance of the seam which can simulate different geometries.

* email: ilarica59@gmail.com, ilare.bordeasu@upt.ro; Phone: 0723650248; dragos.utu@upt.ro; Phone: 0723742252 


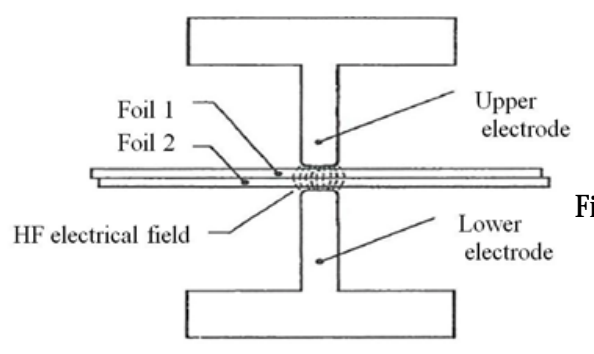

Fig. 1 Description of symmetrical HF welding

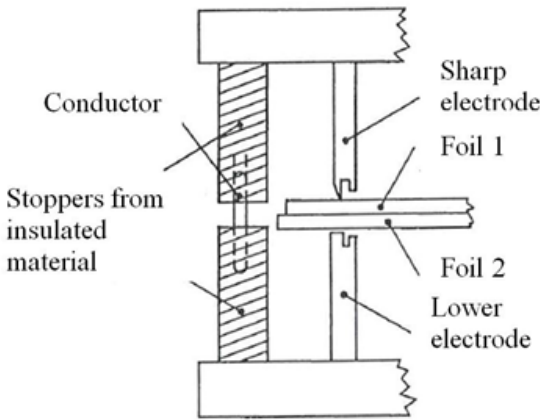

Fig. 2 Description of combined symmetrical HF welding

The aim of the paper is to analyze the thermal gradient variation according to the thickness foils which are welded. For this are used polyvinyl chloride (PVC) foils reinforced with textile material having $0.4 \pm 0.1 \mathrm{~mm}, 0.6 \pm 0.1 \mathrm{~mm}$ and $1 \pm 0.1 \mathrm{~mm}$ thicknesses.

The thermal gradient is drawn up using the equipments described in figure 3.

The thermocouples are displayed in the cross section of HF welding assembly (fig. 3) as follows:

- thermocouple 1 is placed between the electrode and upper foil 1;

- thermocouple 2 is placed in the middle of upper foil 1

- thermocouple 3 is placed between the foils 1 and 2 ,

- thermocouple 4 is placed in the middle of lower foil 2.

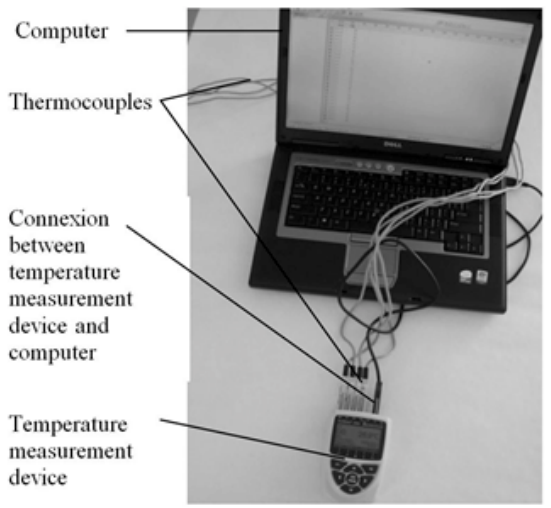

Fig. 3 Description of equipments for thermal gradient determination

As testing method, in order to determine the mechanical strength of the HF welded joints made from different sizes PVC sheets, a PEUGEOT S.A. D41 1033 was considered which has as imposed requirement a mininium value of the breaking force of $35 \mathrm{~N} / 50 \mathrm{~mm}$ [5-7].

The device used for measuring the breaking force [8] is composed of a fixed part which fix the test sample by means of a bolt and a movable carriage with clamping parts which slide by means of a screw - nut mechanism.

The thermal gradient during HF symmetrical welding

The recorded data of HF welding of $0.4 \mathrm{~mm}$ PVC foils are statistically processed using second degree (quadratic) regression by specialized Minitab software which can evaluate the temperature variation into the welded material according figures 4 and 5 .

The quadratic equation of the temperature gradient in the PVC film obtained from regression is marked with (1):

$$
\log T=1.57757+4.14014 a-6.44261 a^{2}
$$

The recorded data for HF welding of $0.6 \mathrm{~mm}$ PVC foils are statistically processed using a specialized Minitab software with quadratic regression function which can evaluate the temperature variation into the welded material according figure 6 and 7 .

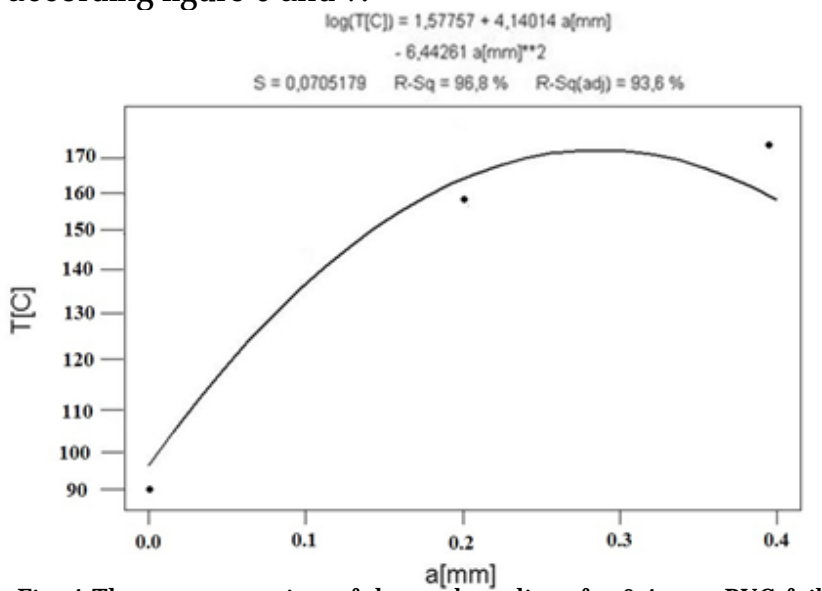

Fig. 4 The representation of thermal gradient for $0.4 \mathrm{~mm}$ PVC foils thickness

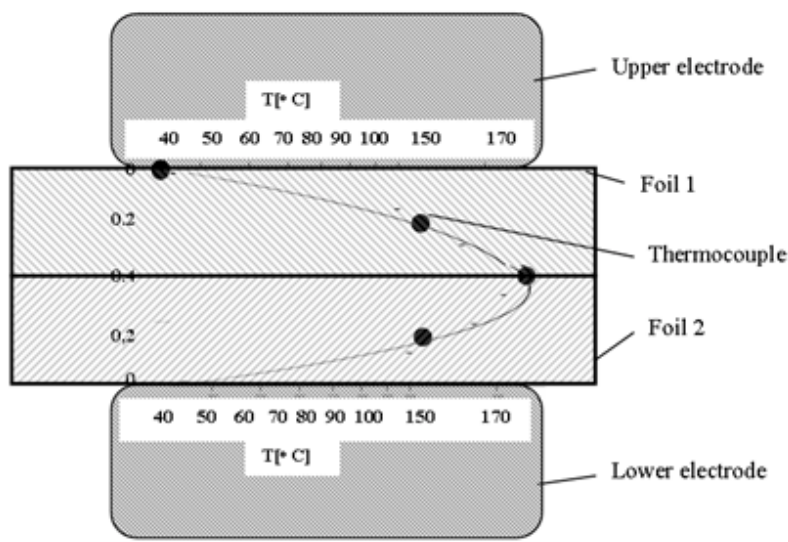

Fig. 5 The representation of thermal gradient in the cross section of welding assembly

The quadratic equation of the temperature gradient in the PVC film of $0.6 \mathrm{~mm}$ thickness obtained from regression is marked with (2):

$$
\log T=1.48968+3.08460 \mathrm{a}-3.11672 \mathrm{a}^{2}
$$

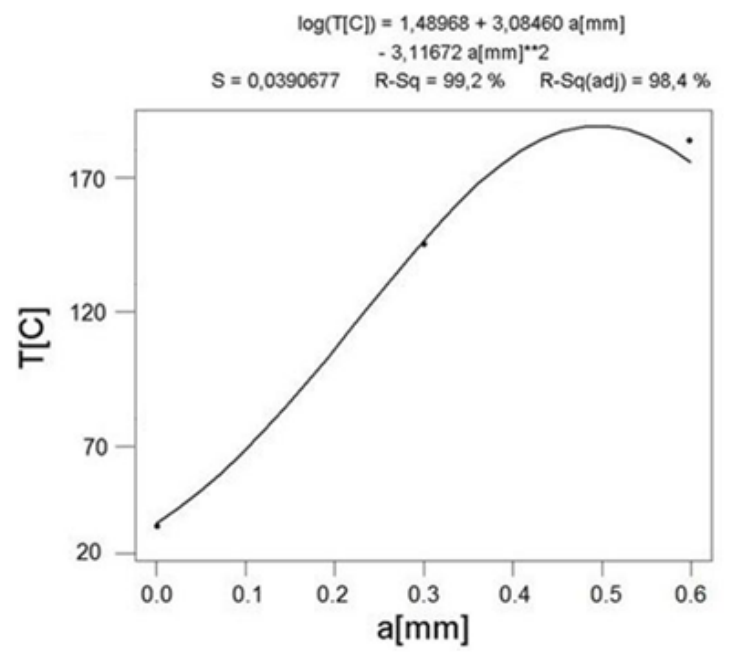

Fig. 6 The representation of thermal gradient for $0.6 \mathrm{~mm}$ PVC foils thickness [1] 


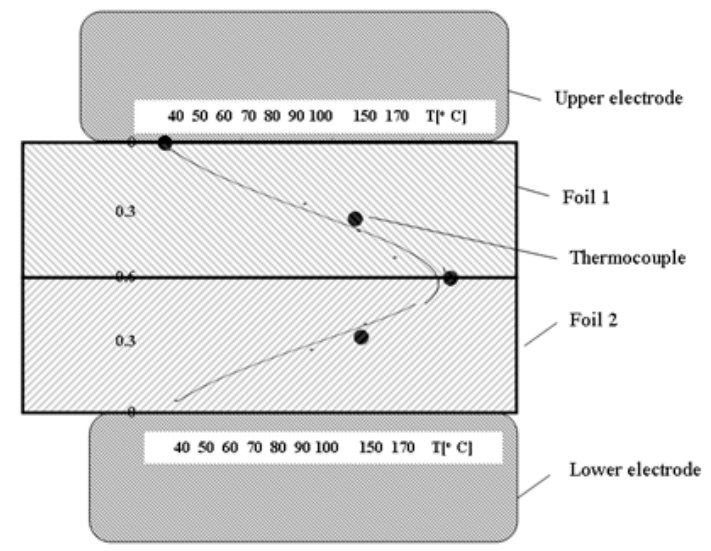

Fig. 7 The representation of thermal gradient in the cross section of welding assembly

Using the same procedure, the temperature variation into the welded material of PVC foils with $1 \mathrm{~mm}$ thickness is represented in figure 8 and 9 . The quadratic equation of the temperature variation in the PVC foils of $1 \mathrm{~mm}$ thickness obtained from regression is marked with (3):

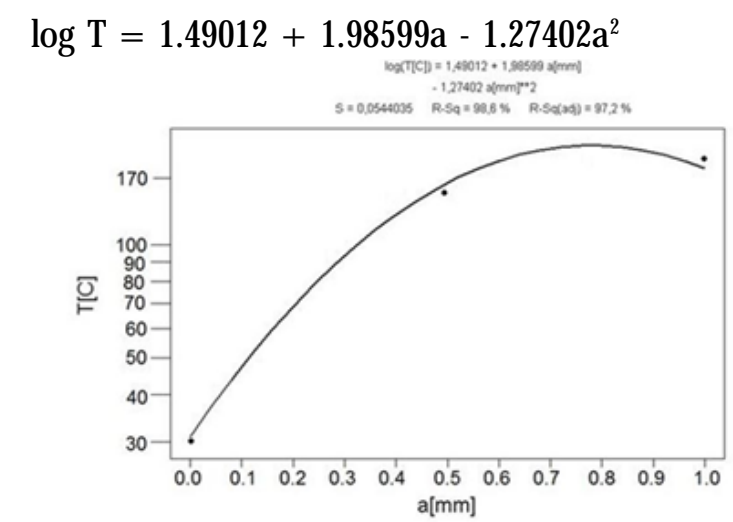

Fig. 8 The representation of thermal gradient for $1 \mathrm{~mm}$ PVC foils thickness [1]

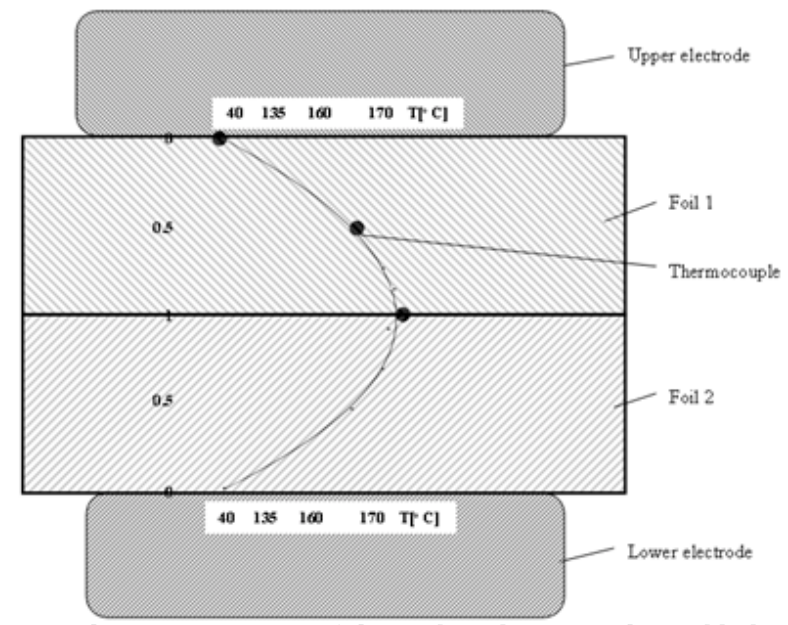

Fig. 9 The representation of thermal gradient into the welded $1 \mathrm{~mm}$ foils

Following the thermal gradient for different thickness of the welding film according to figures 4 to 7 it is observe that for thinner foils $(0.4 \mathrm{~mm}$ and $0.6 \mathrm{~mm})$ the temperature gradient is higher due to heat losses, which request a higher HF welding field.

In figure 9 it is shown that, for the foils with $1 \mathrm{~mm}$ thickness, the thermal gradient has low values which are kept into the electrodes area. The heat needed in the contact area of the foils, in order to obtain the welded joint, has to develop a temperature which provides the material flowing. Through applying a minimal pressure the welded joint is achieved.

\section{Findings}

- the heat loss into the electrodes cannot be avoided and it is considered a key characteristic of the HF welding process;

- the heating effects for the foils with $0.4 \mathrm{~mm}$ thickness (fig. 5) shows an extension of the temperature variation on the edge of electrodes contact area, which makes more critical the cooling process and increase the cooling time after welding.

Thus, from the experimental data synthesized in previous diagrams, it can be concluded that increasing of PVC foils thickness keep the heating effect in the electrodes contact area and make the welding process more stable. The following results represent the determination of the geometrical and mechanical characteristics for HF welding of $0.6 \mathrm{~mm}$ thick PVC foils.

\section{The quality of HF welded joints from polymers foils} Geometrical characteristics

The appreciation of the welded joints is based on the geometrical characteristics fulfillment of the welded area, appearance and exploitation requirements that makes the welding process competitive on the market. These features are macroscopically checked and are clearly defined according to customer expectations.

As it can be seen in figure 10a and 10b the visual aspect of the welded joint is in concordance with the electrodes geometry presenting no defects, its width has to be constant, the welding steps must be visible like seen in figure 11 .
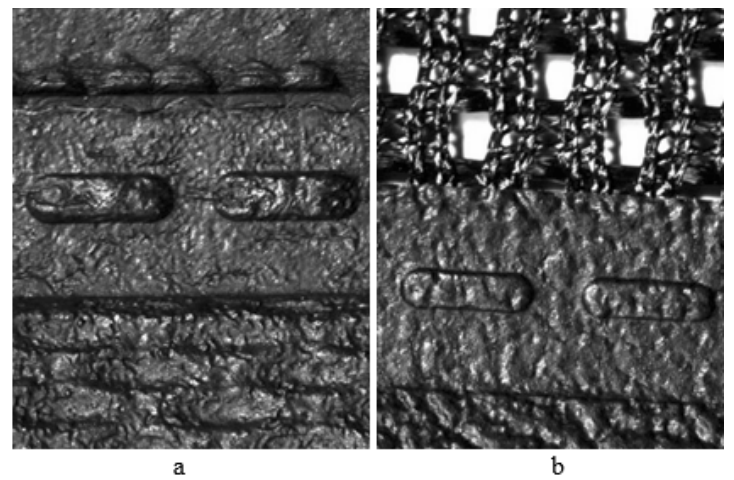

Fig. 10 The visual appearance of symmetrical HF welding which simulate the weld seam

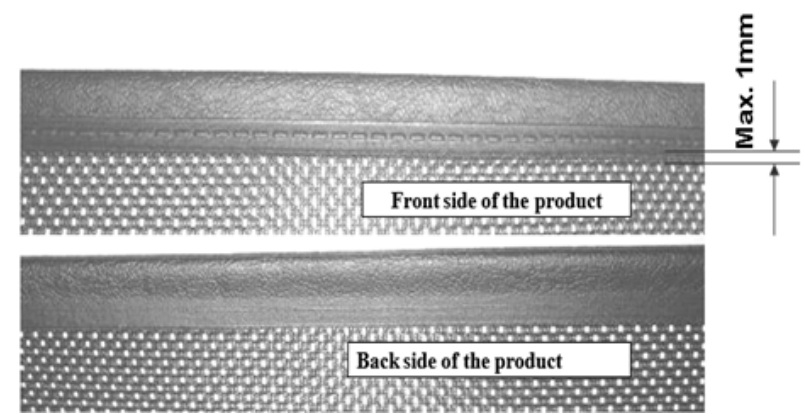

Fig. 11 Representation of HF welding seam width (front and back side of the product)

Also, as it can be seen in figure 12 , the image was recorded at microscope type CL 1500 ECO0, the overlapping deviation of the PVC foil does not exceed 1 $\mathrm{mm}$.

For welded joint appreciation all these geometrical characteristics have to be fulfilled, which means that the products are conform from aspect point of view. These characteristics are macroscopic checked and are defined according to customer expectation. 


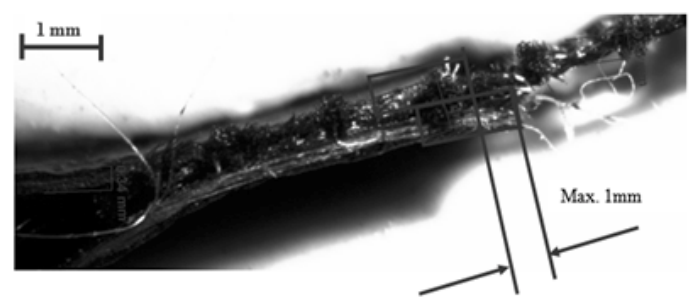

Fig. 12 Representation of PVC foils deviation

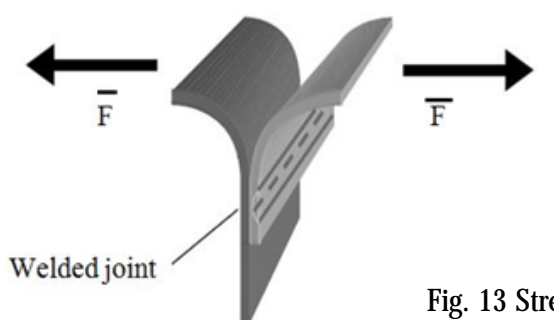

Fig. 13 Strength testing method
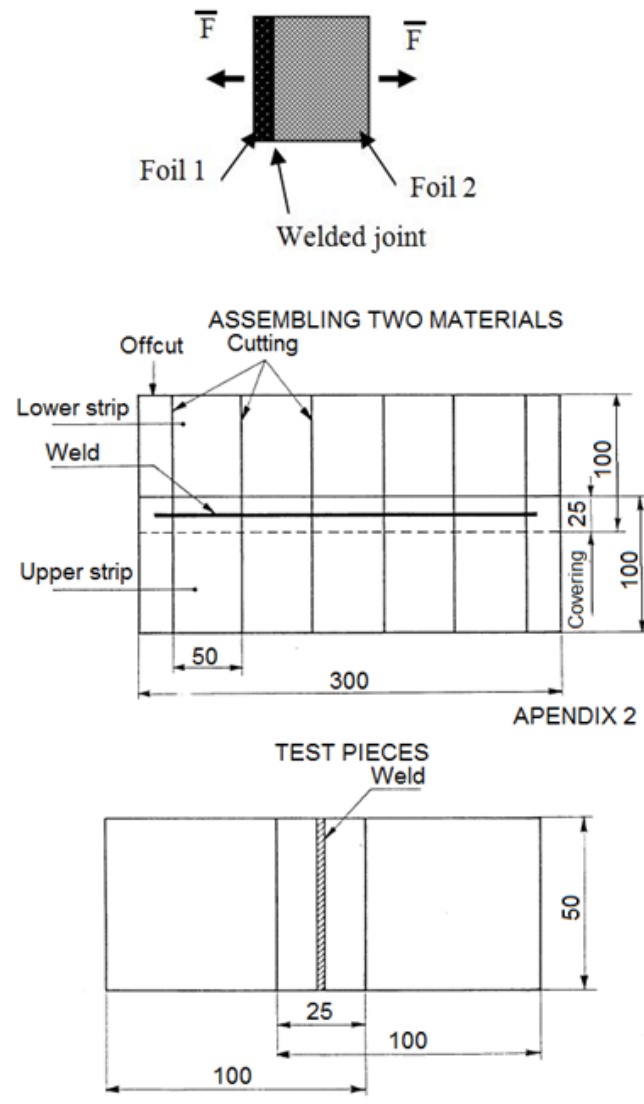

Fig. 14 Sample cutting method

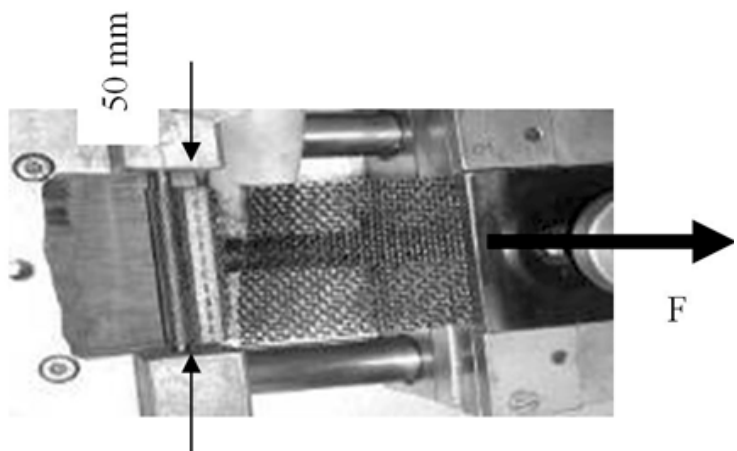

Fig. 15. Testing device

Mechanical characteristics

Because, the mechanical characteristics cannot be visual evaluated, the welding joint was tested through destructive tests. As testing method, in order to establish the weldability of the materials, it has been used the PEUGEOT S.A. test method D41 1033 which requires a

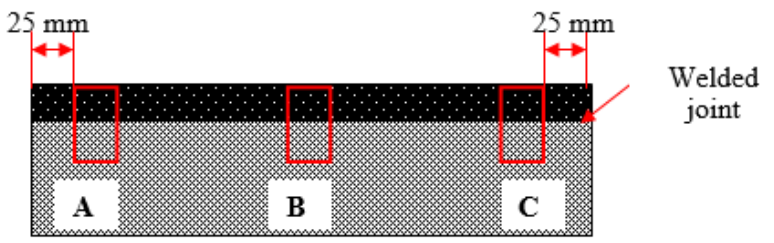

Fig. 16 Sketch of sample cutting

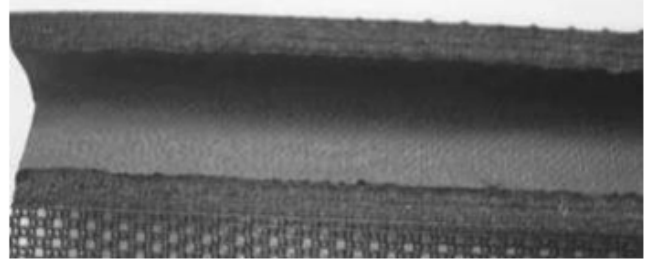

Fig. 17. The melt material distribution after welding

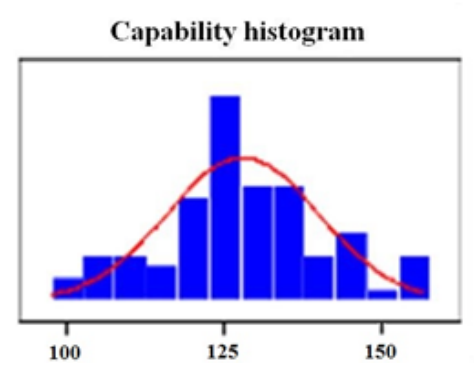

Normal probability plan

$\mathrm{b}$

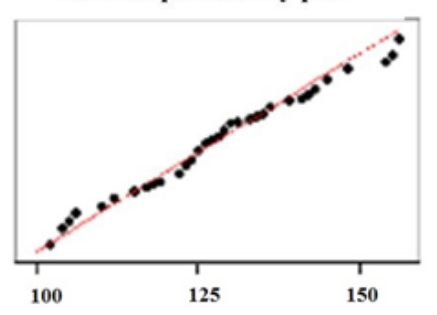

Fig. 18. Capability of the welding process for $0.6+/-0.1 \mathrm{~mm}$ PVC foils

minimum breaking force of $\mathrm{F}=35 \mathrm{~N} / 50 \mathrm{~mm}$, as shown in figure 13.

According to this method the samples cutting is done according to figure 14 .

The cut samples were checked according to mentioned method using the device presented in figure 15 [7].

Because, the melted material distribution after the welding process is a key characteristic for that strength tensile to be constant along the welded joint, the testing steps are:

- the samples are fixed to the test device

- the applied load increases constantly until the material or welded seam it breaks. These force values are recorded as strength tensile and represents the mechanical characteristic of the welded joint.

Using the presented testing method it will be measured and recorded the breaking forces on a number of 75 samples taken from 25 welded parts, three zones from the welded seam, as it can be seen in figure 16 .

After the destructive attempts, the distribution of the melt material at macroscopic level, is constant, as it can be seen in figure 17.

The measured strength tensile values were statistically displayed using the Gauss bell distribution, from figure 18, which shows the graphical representation of the breaking forces values in the form of the capability diagram.

From this histogram (fig. 18a) it can be observed a relative uniformly distribution of the breaking force in the range of 100-150N. According to normal probability plot diagram (fig. 18b) there are no deviations from the straight line which suggest any departures from normality.

It can be concluded that the technological parameters established experimentally for the high frequency current welding process of the used PVC foils show that this is stable both as adjustment and precision, providing the required quality requirements for the welded joints. 


\section{Conclusions}

The HF symmetrical welding is the most indicated method for thermoplastics joining due to the advantage of symmetrical distribution of the electrical field lines which provide the highest energetic efficiency from the HF welding methods.

From this reason the welded joint strength obtained with symmetrical HF welding is better than other alternatives (pressure welding, ultrasonic welding, etc).

The thermal gradient for HF symmetrical welding is dependent by the thermoplastics thickness.

So that the welding process is more stable by increasing the PVC foils thickness because the heating effect is kept in the electrodes contact area.

\section{References}

1.LORENSCHEIT K.: Frequenz Technik, Verlag, Mainz, 1997/1998, Germany

2.J ACSCH E., CHETARITI D. Materiale plastice poliamidice, Bucuresti. Ed. Tehnica, 1988.

3.BAlJAL, M.D.: Plastics polymer science and technology, EDITION WILEY-INTERSCIENCE, SUA, NEW YORK, 1982

4.POPESCU, M.: Tehnici de imbinarea materialelor plastice, Editura Politehnica Timisoara, 2004
5.TOSA, DJ, SERBAN, VA; CODREAN, C; BUZDUGAN, D; STOICA, M, Dual phase bulk metallic glasses fabricated by hot pressing using two different types of glassy alloy pow der, J ournal of Optoelectronics and Advanced Materials, Volume: 17, Issue: 7-8, Pages: 1026-1031, 2015.

6.MITELEA, I., VARZARU, N., POPOVICI, D., POPESCU, M., BORDEASU, I., Researches of High Frequency Welding Process Validation for Same Polymers, Mat. Plast., 45, no. 3, 2008, p. 289

7.MITELEA, I; VARZARU, N; BORDEASU I; POPESCU M; The High Frequency Welding Aptitude of Thermoplastic Polymers, Mat. Plast. 46, no. 1, 2009, p. 101

8.MITELEA,I.; VARZARU, N., BORDEASU, I., SCURTU, D., Failure Analysis of High Frequency Welding Fixed Joints of Thermoplastic Polymers, Mat.Plast.,46, no. 4, 2009, p. 439

9.BEJ , A., BORDEASU, I., MILOS, T., BADARAU, R., Considerations Concerning the Mechanical Strengh of Wind Turbine Blades made of Fiberglass Reinforced Polyester, Mat. Plast., 49, no. 3, 2012, p.212 10.UZELAC, D., BIKIC, S., DURDEVIC, M., BORDEASU, I., Alteration of Polyethylene Pipe Wall Thickness after Squeeze of-tool, Mat. Plast., 48, no.1, 2011, p.12

Manuscript received: 21.02.2017 